
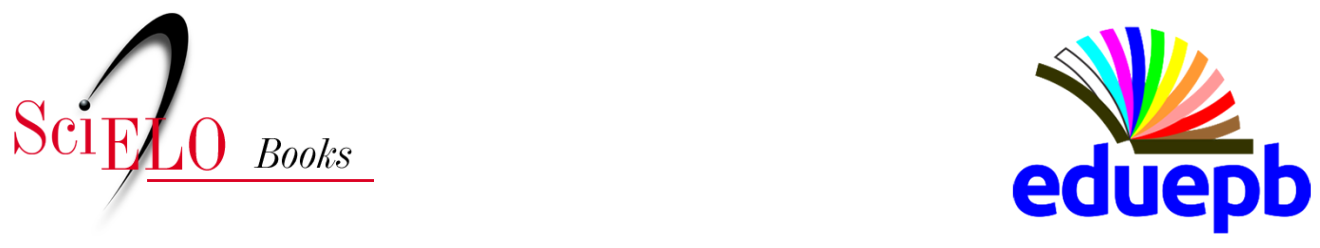

\title{
Influências e Legados \\ Angelo Oswaldo - Sem cultura, o desenvolvimento se torna frágil e vulnerável
}

\author{
Cidoval Morais de Sousa \\ Milena Barros Marques dos Santos
}

\section{SciELO Books / SciELO Livros / SciELO Libros}

SOUSA, C. M., and SANTOS, M. B. M. Angelo Oswaldo - Sem cultura, o desenvolvimento se torna frágil e vulnerável. Interviewed: Angelo Oswaldo. In: SOUSA, C. M., THEIS, I. M., and BARBOSA, J. L. A., eds. Celso Furtado: a esperança militante (Depoimentos): vol. 2 [online]. Campina Grande: EDUEPB, 2020, pp. 271-281. Projeto editorial 100 anos de Celso Furtado collection. ISBN: 978-65-86221-11-4. https://doi.org/10.7476/9786586221671.0012.

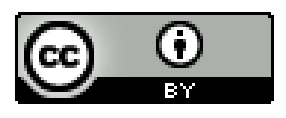

All the contents of this work, except where otherwise noted, is licensed under a Creative Commons Attribution 4.0 International license.

Todo o conteúdo deste trabalho, exceto quando houver ressalva, é publicado sob a licença Creative Commons Atribição 4.0.

Todo el contenido de esta obra, excepto donde se indique lo contrario, está bajo licencia de la licencia Creative Commons Reconocimento 4.0. 


\section{Angelo Oswaldo}
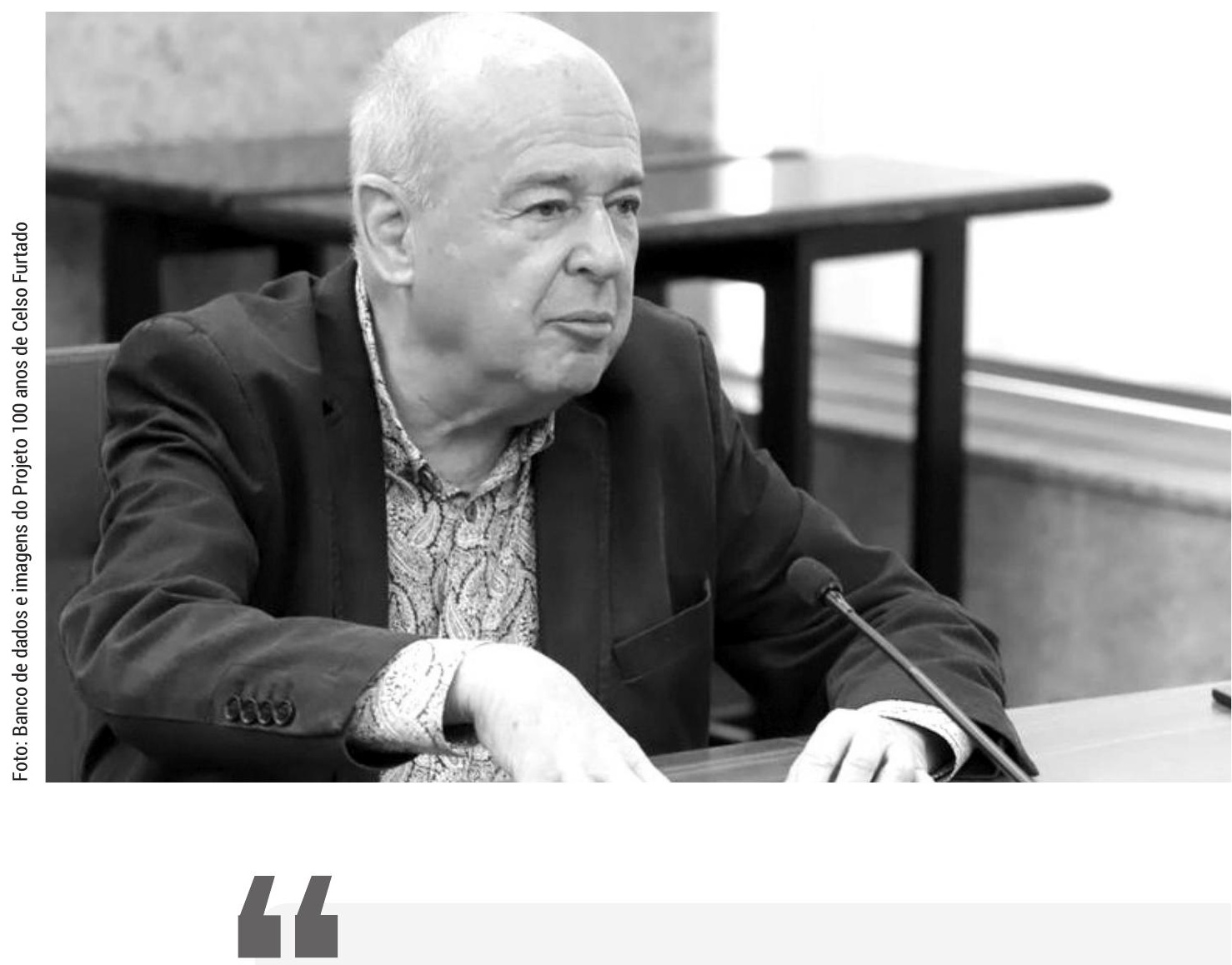

Como intelectual, Celso Furtado sempre abordou a questão cultural como um dos pontos seminais da vida do país e do seu desenvolvimento socioeconômico. Não só na obra acadêmica, mas também na militância política... A partir do prisma cultural, ele compreende e narra o percurso e enfatiza o papel da cultura na construção possível do futuro. 0 legado de Celso Furtado como ministro é o entendimento de que, sem se fundar na cultura, o desenvolvimento se torna frágil e vulnerável, incapaz de responder à realidade do país e de sua população. 


\title{
Sem cultura, o desenvolvimento se \\ torna frágil e vulnerável
}

\author{
Cidoval Morais de Sousa \\ Milena Barros Marques dos Santos
}

\begin{abstract}
A ngelo Oswaldo de Araújo Santos ${ }^{3}$ conheceu Celso Monteiro Furtado em 1974, em Paris. Furtado - paraibano de Pombal (1920-2004), exilado desde 1964 do Brasil pela ditadura militar - era professor da Sorbonne e fora convidado a integrar uma banca de defesa de doutorado na capital francesa. Angelo Osvaldo, como é mais conhecido no mundo político-cultural, compartilhava o entusiasmo de numerosas pessoas que queriam ver o intelectual em ação. O paraibano não comportava apenas a fama de grande economista. Ele era também, dentre outras coisas, advogado, jornalista, escritor, servidor público, planificador, criador da Sudene, historiador. Um homem de pensamento e ação, um teórico do desenvolvimento socioeconômico, um homem de cultura e, de certo modo, um estadista. A Angelo Oswaldo, o homem discreto e reservado, de observação culta e fascinante lembrava um poema de João Cabral de Melo Neto: conciso e surpreendente.
\end{abstract}

1 Jornalista, Doutor em Geociências pela Unicamp, professor e pesquisador da Universidade Estadual da Paraíba (UEPB), vinculado aos Programas de Pósgraduação em Desenvolvimento Regional e Ensino de Ciências e Educação Matemática. Colabora com o PPGCTS da UFSCar.

2 Jornalista, Mestranda em Desenvolvimento Regional (PPGDR UEPB), Especialista em Gestão Pública, documentarista.

3 Jornalista, escritor, curador de arte, advogado e gestor público. Nasceu em Belo Horizonte, MG, em 1947. Na gestão de Celso Furtado no Ministério da Cultura (198688), foi secretário do Patrimônio Histórico e Artístico Nacional (IPHAN), chefe de Gabinete e ministro interino. Exerceu os seguintes cargos: prefeito municipal de Ouro Preto, MG (1993-96, 2005-08, 2009-12), presidente do Instituto Brasileiro de Museus, IBRAM (2013-14) e secretário de Estado de Cultura de Minas Gerais (19992002, 2015-2018). É membro da Academia Mineira de Letras e da Academia Brasileira de Arte, sendo sócio do IHGB e IHGMG. 
Pouco mais de uma década depois, Furtado e Oswaldo trabalhariam juntos no Ministério da Cultura. O momento era delicado: fim do período de ditadura militar no Brasil; impedimento e morte do presidente eleito indiretamente, Tancredo Neves; posse, como presidente, do então vice-presidente José Sarney; criação do Ministério da Cultura e deslocamento de seu primeiro ministro, José Aparecido de Oliveira, para o governo do Distrito Federal. O sucessor de Aparecido no Ministério, Aluísio Pimenta, não deu certo e Celso Furtado foi indicado ao cargo de ministro da Cultura em janeiro de 1986. Na opinião de Oswaldo, Furtado levou confiança, equilíbrio, sobriedade e responsabilidade ao Ministério da Cultura. Era um homem de ação que sabia pensar o Brasil. Os meios culturais reagiram positivamente. O pensador paraibano consolidou o Ministério da Cultura. A partir dos esboços de José Aparecido, Furtado definiu um organograma simples e objetivo, clarificou vertentes e orientou a administração direta e indireta, de forma lúcida e afirmativa. Destacou quatro eixos de atuação para o desempenho da pasta: patrimônio cultural; ação dinâmica da cultura; dimensão social da cultura; e a comunicação e o intercâmbio internacional.

A questão cultural, em Furtado, na compreensão de Oswaldo, era um dos pontos seminais da vida do país: cultura e desenvolvimento deviam ser percebidos como vetores de um mesmo processo. Chamava atenção para a cultura nas escolas, nos presídios e nos asilos, destacava o advento da transformação tecnológica, analisava a globalização, apontava disparidades regionais e a necessidade de compreender os desafios das cidades e dos territórios. A atuação política de Furtado, nas lembranças de Angelo Oswaldo, sempre esteve voltada para a causa republicana e democrática, para superação da miséria e valorização da originalidade do Brasil como povo e país. Inovou ao se preocupar com a dimensão da cultura no cotidiano dos cidadãos e mostrou que o caminho da reconstrução, após duas décadas de regime autoritário, seria mais difícil e penoso sem a luz da cultura a guiar um processo de participação e envolvimento da sociedade. Como ministro da Cultura, seu legado foi o entendimento de que o desenvolvimento sem se fundar na cultura se torna frágil e vulnerável, incapaz de produzir mudanças na realidade do País.

Direto de Ouro Preto, na primeira semana de maio de 2020, em meio à Pandemia de Covid-19, Angelo Oswaldo aceitou dar entrevista ao Projeto 100 anos de Celso Furtado, recebendo perguntas e devolvendo as respostas por e-mail. Confira, a seguir, a íntegra da entrevista 


\section{Entrevista}

- Como foi que o senhor conheceu Furtado? Como se deu sua aproximação com ele? Pode nos contar / relatar algum fato desse período?

Conheci Celso Furtado em 1974. Eu morava em Paris, como estudante, e fui chamado por Linda Nemer, amiga mineira que fazia doutorado, para comparecer a uma defesa de tese em Nanterre, a fim de ver Celso Furtado. Cheia de entusiasmo, ela falava da emoção de assistir, pela primeira vez, o grande intelectual exilado em ação. Compartilhando essa expectativa, acompanhei-a a Nanterre, para onde acorreram numerosas pessoas que desejavam, de igual modo, ver e ouvir Celso Furtado, integrante da banca examinadora de um doutorando. Ele foi o centro das atenções. Pude cumprimentá-lo, ao final, manifestando-lhe minha admiração. Mais tarde, quando de sua volta ao Brasil, logo tivemos várias oportunidades de reencontro. Era um homem extremamente discreto e reservado, mas dotado de humour e pronto a enfeixar, em poucas palavras, uma observação culta e fascinante sobre os mais diferentes assuntos. $\mathrm{O}$ casamento com minha amiga Rosa Freire d'Aguiar e a nossa amizade com o historiador Francisco Iglésias nos aproximaram sempre mais. Recebi o casal em Belo Horizonte e Ouro Preto em várias oportunidades, na época em que ele teve uma atuação decisiva no processo de transição política, ao final do regime autoritário.

- Para o senhor, quem era/foi o homem Furtado (para além de sua obra, o ser humano Furtado)?

Eu o vejo como um dos maiores pensadores do século XX, no espaço latino-americano e no contexto mundial do seu tempo. Ele não comporta um rótulo, como muitas vezes querem atribuir-lhe, por ter sido muito mais do que o economista largamente reconhecido. $\mathrm{O}$ advogado, tenente da FEB, jornalista, escritor, servidor público, ministro de Estado, planificador, criador da Sudene, diplomata, historiador e professor foi um homem de pensamento e ação, um teórico do desenvolvimento socioeconômico, um homem de cultura e um estadista, no sentido de ter contribuído para o aprimoramento das instituições públicas e o descortino de uma nova visão das realidades, em especial do Brasil. Gosto de dizer que Celso me lembra um poema de João Cabral de Melo Neto, conciso e surpreendente. 
Parece seco tal como o agreste, mas tem a generosidade da cacimba que sacia e refresca. Nada nele excede, nada é supérfluo. A figura esguia e hierática, o rosto bem talhado, o olhar firme, tudo nele irradiava um impacto. Rosa Freire d'Aguiar, entre o charme e a extroversão, culta e informada, com a sensibilidade de uma jornalista de texto literário e tradutora premiada, transformou a vida de Celso, a partir de 1978. Sem perturbar-lhe o ensimesmado do intelectual em permanente reflexão

e as reservas do temperamento sóbrio, quase austero, ela trouxe-o para a claridade e extraiu-lhe o prazer da alegria, exercido a dois em perfeita harmonia. Ele demonstrava admirar o sorriso de Rosa e o sabor de sua palavra ágil e pertinente. Depois da morte de Celso, Rosa Freire d'Aguiar dedicou-se, de modo esplêndido, a levantar e publicar a obra completa e os inéditos, como faz agora com a correspondência, o que mantém o grande autor presente, acessível e estudado. O Centro Celso Furtado, criado no Rio de Janeiro, deve-se ao zelo e ao desvelo de Rosa.

\section{- O que mais lhe tocou na obra de Furtado e em que ela lhe} influenciou, digamos, politicamente?

A minha geração, que emerge nos anos 60 e 70, teve em Celso Furtado uma referência maior. Ele foi cercado de entusiasmo, admiração e respeito, pela atuação na Sudene e pela reflexão crítica sobre o drama da América Latina. Lembro-me de José Aparecido de Oliveira, o primeiro titular do Ministério da Cultura e secretário particular do presidente Jânio Quadros, dizer que a varredura janista parou diante de Celso Furtado, o único alto dirigente da gestão Juscelino Kubitschek convidado a permanecer no governo oposicionista que se empossara, em razão da autoridade moral, intelectual e política do criador da Sudene. Celso foi criticado, fustigado e agredido pela direita, mas nada atingiu-lhe a aura de quem fazia o certo na hora certa e antecipava o futuro, ao reverter a geografia da pobreza e elucidar o simulacro do subdesenvolvimento. Entrei na UFMG em 
1967, e entre todos os universitários ele era o autor mais lido, citado e comentado. Celso Furtado nos ensinou a pensar o Brasil.

- Antes de trabalharem juntos, a obra de Furtado chegou a influenciar suas ações ou existe um Ângelo político antes e outro depois de Furtado?

A confiança por ele depositada em minha atuação no Ministério da Cultura conferiu-me um papel inesperado e extraordinário, que repercute ainda agora em cada dia da minha vida.

- Como foi que o senhor foi convidado a trabalhar com ele? Pode contar um pouco dessa trajetória?

Quando ele assumiu a pasta da Cultura, em janeiro de 1986, após a sua posse, fui entregar-lhe o cargo de secretário do Patrimônio Histórico e Artístico Nacional. O IPHAN, hoje Instituto, era então uma Secretaria do Ministério. Celso disse que eu devia continuar, por ser uma pessoa da área do patrimônio cultural e conhecer bem o Ministério, ali me achando desde a sua criação por José Aparecido de Oliveira, na sequência de ele haver sido também o primeiro secretário de Estado de Cultura de Minas Gerais e criador do Fórum Nacional dos dirigentes estaduais do setor. E me pediu que acumulasse, interinamente, a chefia de seu gabinete, até que viesse do Rio um amigo convidado para o cargo. Poucos dias depois, indicou meu nome ao presidente da República para ser nomeado ministro interino, já que teve que voltar à Bélgica, a fim de despedir-se oficialmente do cargo de embaixador brasileiro junto à Comunidade Europeia. E explicou: "No meu tempo de DASP, o chefe de Gabinete respondia pelas funções políticas da pasta; o secretário geral, pelas questões administrativas". E rompeu a nova praxe, pondo-me como seu substituto interino.

- O senhor, que era um homem público vinculado à cultura, olhando para aquele momento, o que Furtado trazia de novo? O primeiro ano do Ministério da Cultura (1985) foi tumultuado. A nova pasta viu-se logo fragilizada, desestabilizada. Seguiram-se o impedimento e morte do presidente Tancredo Neves, o deslocamento do ministro José Aparecido de Oliveira para o governo do Distrito Federal, pelo presidente José Sarney, as dúvidas na escolha do sucessor e o insucesso da gestão do ministro Aluísio Pimenta, 
em meio a uma saraivada de críticas. Celso Furtado trouxe confiança, equilíbrio, sobriedade, responsabilidade. Os meios culturais reagiram positivamente à sua nomeação. Um grande intelectual e um homem de ação, assim era saudado, ainda que, para alguns desavisados, sempre numerosos, parecesse estranho um economista na pasta da Cultura. Celso lembrava, então, que Keynes, o notável economista inglês, teve no governo britânico importante atuação exatamente no campo cultural.
Celso Furtado trouxe confiança, equilíbrio, sobriedade, responsabilidade. Os meios culturais reagiram positivamente à sua nomeação. Um grande intelectual e um homem de ação, assim era saudado, ainda que, para alguns desavisados, sempre numerosos, parecesse estranho um economista na pasta da Cultura.

Todos esperavam, contudo, que como um mestre da economia e ex-ministro do Planejamento viesse enfim a tornar realidade a sonhada lei de incentivo à Cultura, batizada de Lei Sarney. É que originalmente o projeto foi apresentado ao Senado pelo presidente, quando ali representava o Maranhão, embora sabendo que os congressistas não tinham direito de propor iniciativas com impacto financeiro para a União. O ministro Pimenta não conseguira concluir um novo texto a ser enviado ao parlamento. Em 2 de julho de 1986, ao fim do primeiro semestre, a Lei Sarney era sancionada, após aprovação pelo Congresso, tendo sido concebida por Celso Furtado.

- As propostas de Furtado lhe chocaram, encontrou resistência lá dentro do Ministério, do Governo?

Celso Furtado foi o consolidador do Ministério da Cultura. José Aparecido traçou um esboço e não teve tempo de concretizar uma estrutura. Aluísio Pimenta não conseguiu empalmar o desafio. Furtado rapidamente definiu um organograma simples e objetivo, clarificou as vertentes e orientou a administração direta e indireta, de maneira lúcida e afirmativa. Um das inovações foi a preocupação com a dimensão da cultura no cotidiano dos cidadãos e da sociedade, a cultura para além das belas letras e das belas artes, como convencionalmente é vista. Praticou conceitos modernos e antecipadores, que depois só foram retomados e reavivados pelo ministro Gilberto Gil. 
- A equipe que vocês montaram tinha sintonia com as ideias furtadianas?

Celso Furtado reunia-se periodicamente com os dirigentes, estava sempre presente e empolgava as pessoas com um discurso claro e preciso. Tinha um carisma ímpar. Ele destacou quatro eixos de atuação para o desempenho do Estado: o patrimônio cultural, a ação dinâmica da cultura, a dimensão social da cultura e a comunicação e o intercâmbio internacional.

\section{- Como era o Furtado Ministro/gestor?}

Celso Furtado era um gestor atento e aplicado. Tinha consciência do significado de uma pasta ministerial para a Cultura como instrumento para a melhoria da qualidade de vida dos brasileiros e o fomento à criatividade. Participou dos debates que ofereceram expressivo contributo à Constituição de 1988, na qual há um robusto trecho dedicado à Cultura. Promoveu o diálogo com o exterior, projetando o país que se redemocratizava e se abria ao mundo, com uma cultura rica, retemperada pela experiência da ditadura e pronta para novos voos. Recordo a audiência a um grupo de representantes da Espanha, que tratava de parceria para a revitalização de um centro histórico brasileiro a ser então escolhido. $\mathrm{O}$ ministro prontamente afirmou: "Só pode ser João Pessoa, a única capital brasileira fundada no tempo do domínio espanhol, com o nome de Filipeia de Nossa Senhora das Neves". Quando levei-lhe a solicitação do Itamaraty de um nome da cultura para receber a Ordem de Rio Branco, de imediato afirmou: Lígia Clark. Resposta que os meios artísticos da época talvez ainda não dessem com tanta convicção. No ano seguinte, o ministro indicou a doutora Nise da Silveira. Era sintonizado com o que havia de melhor no país.

- Que síntese o senhor poderia fazer das proposições de Furtado para o desenvolvimento da Cultura no País?

Celso Furtado sabia pensar o Brasil. Quando assumiu o Ministério da Cultura, ele já havia começado a escrever suas memórias, o esplêndido 
painel autobiográfico que vai da fantasia organizada à fantasia desfeita. Nessas páginas, está evidente que a cultura é a origem e a força motriz dos lances que compõem o processo histórico e as possibilidades do desenvolvimento real do país. A partir do prisma cultural, ele compreende e narra o percurso e enfatiza o papel da cultura na construção possível do futuro. O legado de Celso Furtado como ministro é o entendimento de que, sem se fundar na cultura, o desenvolvimento se torna frágil e vulnerável, incapaz de responder à realidade do país e de sua população.

- Em algum momento o senhor escreveu que a fama de Furtado "Impedia que as pessoas vissem, coexistindo no cientista econômico, o intelectual, o humanista, o escritor, o homem de cultura, o intérprete sensível das realidades do país e do Terceiro Mundo". Pode nos falar um pouco sobre isso? Isso atrapalhou o projeto Furtado para a cultura?

O principal problema enfrentado pelo ministro Furtado foi a pressa e a ganância com que certos setores da produção cultural, sobretudo no campo do espetáculo, se arvoraram em prestidigitadores da Lei Sarney. O insucesso na obtenção de patrocínio naqueles momentos iniciais levou a duras - equivocadas e superficiais, entendo eu - críticas ao mecanismo criado pelo ministro e sua gestão pelos órgãos da pasta, bem como à mobilização nervosa de artistas. Confundia-se cultura com showbiz. Por sobre as iniciativas pioneiras do ministro, prevaleceu nas manchetes o acirramento de ânimos sobre o dia a dia da lei de incentivos. Pouco mais tarde, todos ficariam perplexos com a canetada do presidente Fernando Collor pondo fim tanto à Lei Sarney quanto ao Ministério.

- Olhando os dois momentos de Furtado Ministro (Planejamento e Cultura) o que o senhor acha que fez diferença na ação política do pensador paraibano?

Vejo como traço comum aos dois desempenhos o compromisso com o Brasil, com o nosso povo e a nossa cultura. Na definição das metas trienais do governo João Goulart e no triênio em que estruturou e implementou a primeira política pública de cultura de iniciativa do governo federal, Celso Furtado foi um brasileiro a serviço da causa republicana e democrática voltada para a superação da miséria e a valorização da nossa originalidade como povo e país. Seu pai, o 
desembargador Maurício Furtado, era um estudioso da cultura popular e escreveu um livro no qual recolheu preciosos registros do folclore paraibano. Certamente como ele, Celso buscou sentir e respeitar a alma do povo brasileiro. O fato de ser nordestino foi preponderante na sua opção pelo estudo do subdesenvolvimento e a participação luminosa na CEPAL, em Santiago do Chile, ao lado do argentino Raúl Prebisch.

- O senhor também disse/escreveu que "as políticas públicas de cultura encontram na sua gestão (Furtado) uma fonte de ideias, conceitos e atitudes coerentes em favor do desenvolvimento da cidadania e da qualidade de vida, a partir de um eixo transcendente, indispensável ao indivíduo e à sociedade". Pode nos falar um pouco mais sobre isso, detalhar, dar exemplos...

Celso Furtado chamava a atenção para a cultura nas escolas, nos presídios e asilos, destacava o advento de transformações tecnológicas, analisava a globalização, apontava as disparidades regionais e a necessidade de compreensão do desafio das cidades e dos territórios. $\mathrm{O}$ acesso à criatividade era para ele a primeira reivindicação. Apoiou o trabalho no campo da cultura afro-brasileira e da cultura indígena e contemplou as vanguardas, como fez numa visita histórica ao Teatro Oficina, em São Paulo. Sabia que o caminho da reconstrução, após duas décadas de regime autoritário, seria mais difícil e penoso sem a luz da cultura a guiar um processo de participação e envolvimento da sociedade. Os textos de Furtado são, de fato, uma fonte generosa para políticas públicas que se baseiem no fortalecimento da inteligência e da sensibilidade dos cidadãos brasileiros.

- Como o senhor sintetiza a relação cultura-desenvolvimento na compreensão de Furtado? Como gestor o senhor chegou a colocar em prática alguma proposição furtadiana?

Como intelectual, Celso Furtado sempre abordou a questão cultural como um dos pontos seminais da vida do país e do seu desenvolvimento socioeconômico. Não só na obra acadêmica, mas também na militância política. Dois anos antes de ser ministro, em 1984, ele havia falado aos secretários de Estado de Cultura, em seminário realizado em Belo Horizonte, para destacar a relevância da cultura no mundo contemporâneo em globalização e as particularidades da reconstrução democrática do país, após anos de censura e repressão ao ânimo 
criativo dos brasileiros. Ele sempre compreendeu cultura e desenvolvimento como vetores de um mesmo processo.

- Furtado está fazendo falta, particularmente nesse momento critico da nossa vida política? O senhor poderia imaginar o que ele diria desse momento?

De Vargas a Lula, Furtado viveu intensamente e atuou como protagonista na história do Brasil. Ele participou de projetos inovadores de Getúlio e JK e saudou o advento de Lula, que foi visitá-lo na rua Conrado Niemeyer, no Rio, logo após a eleição, em 2002. Morreu dois anos depois, pelo que foi poupado das amarguras desde então acumuladas no trânsito da História. Não merecia que o país ao qual tanto se dedicou escrevesse essas páginas medíocres e terríveis que fazem a crônica do ano do seu centenário.

- O senhor ainda tem esperança? Que lições de Furtado podem nos iluminar nessa conjuntura?

Celso gostava de dizer, e sempre me recordo, que era um "optimista", pronunciando o "p" da velha grafia. Essa é mais uma lição que nos deixou. Ainda que seja longo o amanhecer, e as trevas persistam, não podemos desacreditar na luz que logo voltará a raiar.

\section{- Economia criativa?}

Um dos temas que marcaram a gestão de Celso Furtado na Cultura foi a ênfase conferida à economia criativa. Ele encomendou e publicou, pela pasta, um estudo da Fundação João Pinheiro, de Belo Horizonte, sobre a economia da cultura, demonstrando a sua força na realidade do país. O potencial de crescimento sinalizava positivamente para a criação de empregos e geração de renda, pelo que o ministro economista evidenciou que o desenvolvimento, na via do terceiro setor, só tinha a ganhar com os investimentos na cultura. A partir dele, a questão ganhou prioridade em todas as pautas. 